\title{
Implementation of Digital Educational Technologies in the Field of Automotive Electronics in Higher Education Institution
}

\author{
Magamed Samedov ${ }^{*}$; Alexander Deryagin²; Ilmir Sahabiev; \\ Myroslav Pahuta ${ }^{4}$, Vadym Rebenok ${ }^{5}$; Nuriya Zakirova ${ }^{6}$ \\ ${ }^{1,2,3}$ Department of Physics, Elabuga Institute of Kazan Federal University. Elabuga, Tatarstan, Russia. \\ ${ }^{4}$ Department of Technological and Professional Science, Drohobych Ivan Franko State Pedagogical University, Drohobych, Ukraine. \\ ${ }^{5}$ Department of professional and life safety protection, T. H. Shevchenko National University «Chernihiv Colehium», Chernihiv, Ukraine. \\ ${ }^{6}$ Naberezhnye Chelny State Pedagogical University. Naberezhnye Chelny, Tatarstan, Russia.
}

ORCIDs: ${ }^{1} 0000-0003-2371-1748, \quad{ }^{2} 0000-0003-1750-2608, \quad{ }^{3} 0000-0002-8679-4248$,

${ }^{4}$ 0000-0003-2305-9390, ${ }^{5} 0000-0002-2943-9725, \quad{ }^{6} 0000-0001-9815-9033$

\begin{abstract}
The purpose of the work is to reveal the traditions, the innovative approach to multifaceted work in the field of digital technologies as an integral part of automotive electronics and pedagogical processes associated with the use of digital educational technologies, implemented in the preparation of future specialists at the natural-mathematical, engineering and technological faculties. The dialectical approach to the organization of the educational process in a university is a guarantee for the success of a pedagogical phenomenon. It includes personal interest, a creative approach on the part of students, teachers to the study of automotive electronics, a variety of types of educational, pedagogical, technological practice, close communication with the representatives of the small, medium, large businesses. The key to the success of this process is the reliance on the achievements of digital, computer technologies implemented in modern cars, a system analysis of design, scientific ideas, concepts, approaches used in the domestic and foreign automotive industry. Another innovation in the work is the implementation of digital educational resources, technical equipment used at the university, including distance learning, a variety of types, forms of monitoring the results of training of future bachelors, masters of the university. The result of the transformations is the increase in the quality of youth's awareness of the implementation of digital technologies in the industry, automobile transport, economics, education, as well as the development of professional competencies in the organization of research, experimental work of students mastering a bachelor or master's degree. It is important to note the promising areas of activity of specialists such as the post-graduate study, defense of candidate and doctoral dissertations, obtaining academic ranks, and occupation of administrative positions.
\end{abstract}

Keywords university training of bachelors, masters; automotive electronics, pedagogical digital innovation, experiment.

\section{INTRODUCTION}

In recent years, the system of training of bachelors and masters in engineering, teaching has made a breakthrough in the development of digital technologies [16; 23], which is comparable to the transition of all automotive electronics to digital, computer technologies, equivalent in nature, to the processes of translation from the frame principle of motor-car construction to the supporting body principle [3].

Indeed, the presence of electronic digital devices in the car makes it possible to secure the road traffic around the world, to organize warranty, post-warranty technical maintenance of the vehicle, to organize a mass pedagogical process for training high-class drivers, ensuring the comfort of life for people of different age groups. The development of this direction began in the $90 \mathrm{~s}[25 ; 40 ; 42 ; 41]$, which led to the fact that a modern car has become a combination of the latest automotive technologies, a way of the practical application of computer digital devices, electronics, which is of great interest to students, especially among students. The use of digital devices in road transport leads to fundamental changes in the implementation of digital technologies for the organization of the pedagogical process, which, in addition to future bachelors and masters, covers the work, the studies of wide groups of the population, including: university teaching staff, the teachers of secondary vocational education institutions (VEI), high school students, pupils of institutions of additional education [32; 17; 36; 34].

Currently, the trends related to the development of automotive innovations, the formation in the automotive industry of a new direction of technological development based on the principles of avionics are clearly seen. Its goal is the creation of unmanned vehicles operating on various types of environmental energy: high-quality gasoline, biofuels, natural gas, batteries, solar energy $[38 ; 39 ; 31 ; 27]$. Another incentive is to reduce accident rates on roads associated with deaths, injuries, ensuring the safe transportation of passengers, improving the comfortable working conditions of drivers, road users, and reducing transportation and financial expenses $[2 ; 37 ; 26]$. 
The main trend in the implementation of innovations of the last decade is related to the fact that in the world market of "buying and selling" electronic components, digital automotive electronics is the most dynamically developing sector, embracing wide categories of the population with its influence and increased interest $[11 ; 4 ; 18 ; 6]$.

There is a consistent pattern: a steady increase in the consumption of electronics by the automotive industry of various degrees of integration leads to the fact that these technologies accelerate the needs of people for the development of the entire digital economy. This trend is noticeable in digital electrical equipment stores selling consumer goods such as refrigerators, vacuum cleaners, washing machines, digital photo-video equipment, computer equipment, mobile devices, which is typical for our country and the world community. The goal of digital innovation - to improve the political, socio-economic state of modern society, to overcome the global crisis is important here $[35 ; 24 ; 19]$.

Given that the purpose of the article is to reveal the traditions and innovations of the teachers of the Department of Physics at the Institute of Physics and Technology in organizing research, experimental work on the use of digital technologies in the study of automotive electronics, it is appropriate to highlight a number of specific, positive factors [8; 33]. This applies to the preparation of future bachelors and masters at the naturalmathematical, engineering and technological faculty of the university, the guarantee of the success of young people in mastering digital technologies of which is the dialectical approach to organizing the educational process [30]. It includes personal interest, creativity on the part of students and teachers in the study of automotive electronics, as a variety of digital technologies implemented in the daily lives of people of different age groups. The number of cars owned by the world's population, the Russian Federation, an increase in their mobility, covering residents of cities and rural areas, acts as significant indicators. Another influencing factor is the variety of types of educational activities of teachers actively introducing digital technologies in the educational process, the development of distance learning, ways of organizing sociopedagogical, technological practice aimed at strengthening the university's ties with state and non-state structures of society, and business representatives $[14 ; 15 ; 10 ; 28 ; 29]$.

In the cases, under consideration, the key to success is the reliance on the latest scientific achievements, the practical use of digital, computer technologies implemented on modern cars. In education, it includes a systematic analysis of design, scientific ideas, concepts, approaches used in the domestic and foreign automotive industry, the implementation of digital educational resources, distance learning, a variety of types, means, forms of control of learning outcomes at a university. The final result of the transformation is to improve the quality of youth's awareness of the implementation of digital technologies in the industry, agriculture, road transport, education, the development of professional competencies, the organization of research, experimental work of the future bachelors and masters $[1 ; 7]$.

The postgraduate studies, defense of candidate and doctoral dissertations, obtaining academic ranks, execution by the specialists of the managerial functions at the level of state and non-state structures of society, the development of technological, JT parks, special economic zone are the promising areas of this work. In this work, the connection between the study of physics, secondary and higher education courses with the academic disciplines of the energy, technological, natural-scientific, and humanitarian fields is clearly observed.

There is one more consistent pattern: future bachelors, masters, as graduates of the Elabuga Institute (one of the oldest pedagogical educational institutions of the Republic of Tatarstan, the Volga-Kama region), are personally interested in finding solutions to the scientific problems associated with the stages of training specialists on car stuff. It covers high school students, students of institutions of secondary vocational education, stages of training of the students of different age groups to improve their skills for working on vehicles. Depending on the category of the group associated with the study of automotive electronics, it is possible to select an object, a subject of study, to formulate its purpose, tasks, methods, a set of technical means, the equipment required for work, determine the final result of this process.

If we take the main sources of electrical energy (an accumulator, a generator) as an object, considering them in the system of the electrical equipment of a car, then the subject of research on the work of future bachelors and masters can be the technical component, the methodology of teaching a subject on automaking. According to the experience, it includes the prospects for the development of the automotive industry, the creation of "unmanned" cars running on traditional, new types of fuel, batteries. As an innovation, the mastering by the students of the subject "Automotive Electronics", which, along with the subjects "Automotive engineering", "The workmanship of a driver-mechanic", includes the operation of automotive microprocessor technology.

\section{MATERIALS AND METHODS}

According to the experience of the teaching staff of EI K(P)FU shows, it's better to start this work with studying the operation of microcircuits (chips) by topics: "Logic elements", "Registers, counters", "Triggers", "Code converters", work of "Arithmetic-logical devices", using the capabilities of computer laboratory equipment programs. Next, the car units, their purpose, the characteristic features of digital integrated circuits should be studied, including operational amplifiers, comparators, timers, linear, switching voltage stabilizers, switches, integrated sensors. It is noted that the greatest professional interest of future bachelors and masters is the study of the operation of digital temperature sensors, acceleration sensors (accelerometers), pressure sensors, hygrometers, a magnetic field (Hall sensors), and other digital devices [3] used in automobile transport. This is realized when studying the educational programs of the courses: motor vehicles, methods for studying automotive electronics, the creation of an educational and methodological complex (EMC) in the educational institution of vocational education on engineering training, their scientific and methodological substantiation. 
The next factor is the analysis of scientific, technical, educational and methodological literature, periodicals, Internet resources, technical documentation of automobile transport, and diagnostic equipment. A special place is given to the analysis of work plans, teacher programs on the functioning of digital devices, the features of the electrical systems used in automobiles, and the activities of factories producing automobile products. The most important direction of students' work under the guidance of teachers is the study of best practices in the pedagogy of the masters of service stations, teachers of institutions of secondary vocational education, automotive engineering teachers, driver classification improvement teachers, automotive specialists and participants in international competitions. The next area of activity of the EI $\mathrm{K}(\mathrm{P}) \mathrm{FU}$ teaching staff is related to the history of the development of foreign and domestic vehicles, the implementation of technologies for their design, operation, including obtaining a driver's license.

\section{RESULTS}

The analysis of the experience of the Republic of Tatarstan in the study of automotive digital technology, actively participated by the teachers and students of EI K(P)FU, shows that this multifaceted work should be considered as a modern technological, educational and research, creative process in the preparation of future bachelors and masters. An important role in this process is played by the methodology for studying digital devices used in automotive electronics, advanced courses in physics, related disciplines, as an academic discipline. Of decisive importance is the activation of intersubject, metasubject communications, which is important for class organizers in classrooms equipped with modern digital, computer devices $[16 ; 35]$.

The approach to teaching university physics courses is changing, including the training of the specialists for VEI institutions. The role of experienced teachers with a long experience in the university, supervising young scientific personnel, is growing. The status of the teacher is changing, the range of his professional, social and pedagogical duties is expanding. In the experience of EI K(P)FU these types of work include: the classes at the "Children's University", the recreation camp "Intelleto", the evenings of science, technical creativity, master classes with school teachers, the teachers of VEI institutions, additional education institutions, where the automotive electronics, the methodology of its study is widely supported $[41 ; 32 ; 17]$.

The authors propose to supplement the curriculum course with several educational blocks to solve the problems related to the research work of the bachelor's and master's training program in the study of digital automotive electronics, the content of which is innovative. The first block includes the history of the development of the foreign and domestic automotive industry. The second one contains a general program for studying car components, elements of electronic equipment of all available models. The third block is concerned with the basic elements of automotive electronics, the methodology for their study in educational institutions of various types. The fourth block includes the individual program of individual devices of the car, its electronic equipment, which contains 12 educational sections as part of the SMC.

Several research areas of work related to the use, implementation of a variety of digital automotive devices were identified by the authors when implementing the curriculum. The first area relates to technologies for conducting demonstration experiments and the operation of automotive electronics. They are based on experiments in electrical engineering, microelectronics, computer technology, laboratory classes for high school students, students, deeply studying physics, related subjects.

The courses of the natural-mathematical cycle, electrical engineering, electronics, digital automotive sensors, and onboard automobile computer are independent educational subjects. The work is based on the scientific concept that the family of digital devices, when studied using computer presentations, professional, amateur videos, software and methodological support for distance learning platforms, provides a rich scientific and technical substantiation for the application of physical laws in robotics, electrical engineering automotive electronics.

The most important element of this process is the solution of specific research problems, a description of work experience in digital microelectronics, a laboratory workshop on the basics of automation, a workshop on "circuitry", microcontroller programming. The system of creative tasks of various types of complexity has been developed based on these technological ideas. It includes the organization of demonstration experiments to verify the operation of DC sources, extending the life of batteries; the diagnostics of alternators, electric motors; the verification of automobile digital sensors, on-board computers, the devices of modern cars. The basis of the work is the organization of training sessions for a complex of laboratory, research, creative activities of future bachelors, masters, under the guidance of university teachers. An analysis of this work makes it possible to note the features of the studied objects related to automotive electronics, which is especially important. It is provided for by the requirements of the Federal State Educational Standards (FSES) and its content is updated every few years. Another direction is the organization of scientific research experiments, the preparation of bachelors in power engineering, taking into account the regional characteristics of the university, the transition to digital technologies used in road transport.

Recently, digital technologies began to be actively introduced into the field of secondary and higher education. They require focused psychological, pedagogical, and high-tech research, including the need to consider the practical use of computer devices and automobile transport programs. This is a milestone factor in the preparation of future bachelors, masters, subject teachers (specialists), solving the problems of using computer technologies, and testing knowledge control [3; 9].

It widely uses a workshop for solving didactic tasks (examples, tasks, analysis of real-life, learning cases) in automotive digital electronics, which improves the quality of research work, specifies its purpose, tasks, content, and practical application. Such studies are related to the measurement of the operation of digital devices used in automobile transport, which is carried 
out according to the principle "verification before ratification". The analysis of such work shows that each student has to deepen his knowledge in such fields as electric power, radio engineering, computer technology, communications, their software, technological processes, and operating conditions.

The temperature sensors; multivibrators assembled by the students; various types of integrated circuits, automotive sensors; digital mobile devices, on-board computers, operation features are the object of study in EI K(P)FU. Independent research includes the logical elements of integrated circuits; digital devices based on the operation of triggers, other microprocessor technology; the workshop on solution of the research problems, problems in automotive electronics.

As an example, let us consider the description of one of the innovative directions in the study of digital automotive electronics implemented at $\mathrm{EI} \mathrm{K}(\mathrm{P}) \mathrm{FU}$, particularly, the possibility of adapting an automated research complex to the implementation of laboratory workshops by future bachelors, masters in automotive electronics, the organization of a research experiment. The most important stages of such work include the correct assembly of the experimental installation, the electrical circuit; the installation of automotive sensors, onboard automobile computer units, their verification; collection, storage of experimental data; machine control of students' knowledge on a 5-point and 100-point system for assessing the level of professional competencies.

When considering the operation of automotive sensors, it is important to set a number of problem-thematic issues. Technologically, using the block system for organizing the educational process, it includes 3 sections:

The first section is the main types of automotive sensors, their classification and functions.

The second section is automotive sensors: purpose, variety, location.

The third section is the organization of a laboratory workshop, research experiments to test the performance of sensors, elements of an on-board car computer.

As is commonly known, a modern automobile consists of many mechanical, electromechanical, electronic components, and optimal engine performance should be ensured regardless of external conditions. When external factors change, the operation of the nodes must adapt to them. In this case, the automobile sensors serve as monitoring devices for the operation of mechanisms of the entire car. For a practical solution to this issue, it should be noted that the role of sensors in the car to ensure its operation without failures, the safety of the driver, passengers increases every year. The data of electronic, digital devices and control devices allow the driver to control the operation of the engine, other car systems, the cost of consumables: fuel, technical fluids, and in time to detect problems that ensure travel safety. For their characteristics, the future bachelors and masters need to know the classification of automotive sensors, which differ in technical parameters, purpose, application features, methods of repair, maintenance, their functions.
There are 3 types of device classes. The first-class devices are responsible for operation, diagnostics of the braking system, steering. The second-class devices control the power plant, suspension, tires, transmission. The third class of sensors is responsible for the protection functions, a comfortable ride, and modern technologies make it possible to manufacture automotive sensors from high-tech materials.

The electronic devices are divided into two groups by design. The first group includes integrated sensors with the availability of intellectual capabilities, which allows reducing the created load on the control unit. The connection of devices of this group is carried out using flexible communication lines. These sensors process signals of low intensity. Another group of electronic devices is classified as a fiber optic type. Their feature is high sensitivity to pollution in automotive components, high-pressure mechanisms. The advantage of these sensors is a poor perception of electromagnetic field interference, and among the shortcomings is a short service life, moreover, these sensors are not suitable for each type of car, since their connection requires special connectors [13].

The general characteristics, types of automotive sensors responsible for the operation of the engine, a brief description of principles of operation are studied next. The most important of them should be noted:

1. The temperature sensor in the car;

2. Crankshaft sensor;

3. Airflow sensor;

4. Oxygen sensor;

5. Throttle sensor;

6. Oil pressure sensor;

7. Engine knock sensor;

8. The angle sensor of the shaft distributor (the engine plays up);

9. ABS Sensor;

10. Fuel level sensor, etc.

At present, wireless [21] and nano-electromechanical sensors and switches [5] are the most promising of them.

With the advent of the fuel injection system, the number of sensors in the car has increased significantly. The electronic control unit (ECU), the on-board computer (OBC) of the vehicle receives, processes a large amount of information, which is necessary for the proper operation of all its systems. Here we study the block of the educational program on car electronics. Moreover, the operation of the vehicle's OBC includes the study of the operation of the built-in (portable) tablet computer with a wide range of operational capabilities: software, wireless network connections, high-speed Internet access, satellite systems, USB 2.0 or 3.0.

In this direction of students' educational activities, their preparation for the defense of a bachelor's, master's degree, the authors rely on a modern fleet of Premium-class cars of 
domestic and foreign production. This makes it possible to evaluate the operation of the dashboard of a car of various models, to analyze the multi-format display, with the participation of experienced drivers (during the period of obtaining a driver's license), the nature of the high-resolution display. A thorough review is made of the operation of the onboard car computer, the assessment of such important systems as climate control, an electronic key, road safety, the operation of the engine and its characteristics, automatic transmission, transmission, fuel consumption, as well as the operation of the reverse sensor, GPS- navigation, audio-video systems, mobile communications and others.

The most important stage of the learning process is the fact that at the end of the course in automotive electronics, each student sums up the intermediate results of their educational activities for the current semester. The general results of the students' work in the classroom are summed up by the teacher, and they are drawn up individually, both in the student's usual five-point assessment of the quality of knowledge, and in the new, innovative 100-point, and, in fact, rating system (BRS) activities of the future bachelor, master. It is assumed that the further development of this direction will be associated with the study of high-temperature electronics [12], modern automobile monitors $[22 ; 20]$.

\section{CONCLUSIONS}

In conclusion, it should be noted that there are a lot of the elements of innovative educational technologies. Based on the author's experience it can be stated that a significant result is obtained when each creative, student group makes extensive use of the possibilities of digital presence in the presentation of educational and methodological material, the best of which are demonstrated in the student audience, conducting classes with students interested in studying digital technologies. The following positive results have been achieved by the authors:

1) Improvement of the nature and content of the processes of mastering automotive electronics, improving the quality of acquired knowledge of the educational and laboratory activities of the educational institution with significant time savings;

2) Visual, musical, sound, colorful presentation of the educational material, the efficiency of all types of documentation, forms of documentation (electronic diary, journal, session sheet, etc.);

3) Individualization of the learning process, education of the student's personality. It is based on a high degree of objectivity of control, self-control of students, analysis, diagnostics, assessment of learning outcomes, the quality of mastery of professional competencies, knowledge, skills;

4) Operational reproduction of educational material, creation of favorable conditions for the organization of educational, scientific experiments, demonstration experiments in electronics, implementation of digital, computer technologies used in automobiles;

5) Creation of a bank of reference, digital technologies for didactic, practice-oriented, research tasks implemented in the process of organizing the educational and creative activities of university teachers and students.

The main result of these transformations is a significant improvement in the quality of youth's awareness of the use of modern electronics, the organization of the research work of students and teachers. It includes the use of digital technologies, physical, technical, energy, pedagogical experiments in the field of studying modern electronics, automotive sensors, an on-board computer, their description, taking into account the car model, scientific research in the organization of pedagogical, production practices of future bachelors, masters. Their most important essence is the continuous improvement of the professional competencies of the participants in the pedagogical process, the development of deep, versatile knowledge, skills in all types of intellectual, educational, scientific, technical, and creative activities. All this is the key to the successful work of the university in the implementation of digital technologies in various fields of activity of students, the entire education system of the Russian Federation for the recent years of its functioning.

\section{ACKNOWLEDGEMENTS}

We are very grateful to the reviewers for their appropriate and constructive suggestions to improve this article.

\section{REFERENCES}

[1] Bochkareva, T. N., Tikhonova, A. N. Analysis and Classification of Digital Educational Resources Used in the Work of a Proactive Teacher. Proceedings International Conference on Developments in eSystems Engineering, DeSE, 2020.

[2] Burkacky, O. Rethinking car software and electronics architecture. McKinsey \& Company, 2018. Available: https://www.gsaglobal.org/wpcontent/uploads/2018/12/3.-Rethinking-car-softwareand-electronics-architecture-Feb-2018.pdf

[3] Deryagin, A. V., Krasnova, L. A., Sahabiev, I. A., Samedov, M. N., \& Shurygin, V. Y. Scientific and educational experiment in the engineering training of students in the bachelor's degree program in energy production. International Journal of Innovative Technology and Exploring Engineering, 8(8), 572-577, 2019.

[4] Dokka, Z., Liubov, N., \& Filatova, I. Problems of oil refining industry development in russia. International Journal of Engineering Research and Technology, 13(2), 2020, 267-270

[5] Farajian, A.A. Physical Review B, 67(20), 2003, 205423. Available: https://journals.aps.org/prb/abstract/10.1103/ PhysRevB.67.205423

[6] Gabidullina, F., Galiullin, R., Khakimova, I., \& Mansurov, I. Elitist education: Historical experience of the russian and tatar peoples. Journal of Social Studies Education Research, 11(1), 2020, 267-280. 
[7] Gafurov, I. R., Safiullin, M. R., Gapsalamov, A. R., Vasilev, V. L. Change of the higher education paradigm in the context of digital transformation: from resource management to access control. International Journal of Higher Education, 9(3), 2020, 1-16.

[8] Gapsalamov, A., Falyakhov, I., Vasilev, V., Sedov, S. Model of Scientific and Methodological Support for Training of Mentors for Vocational Education System in the Conditions of Digitalization. Paper presented at the 1st International Conference on Business Technology for a Sustainable Environmental System (BTSES-2020). E3S Web of Conferences, 159, 2020. doi:10.1051/ e3sconf/202015909016

[9] Gendler, S. G., Rudakov, M. L., \& Kuznetsov, V. S. Evaluation principles of the dust influence of mining enterprises on the environment. [Kalnrūpniecības uzn̦ēmumu putekl̦u ietekmes uz vidi novērtēšanas principi] Latvian Journal of Physics and Technical Sciences, 56(3), 62-69, 2019. doi:10.2478/lpts-2019-0020

[10] Glotko, A. V., Polyakova, A. G., Kuznetsova, M. Y., Kovalenko, K. E., Shichiyakh, R. A., \& Melnik, M. V. Main trends of government regulation of sectoral digitalization. Entrepreneurship and Sustainability Issues, 7(3), 2020, 2181-2195. doi:10.9770/jesi.2020.7.3(48)

[11] Hong, W.S. and Chul M.O. Journal of the Korean Welding and Joining Society, 31(3), 2013, pp. 22-30. Available: https://doi.org/10.5781/kwjs.2013.31.3.22.

[12] Johnson, R. W. IEEE Trans. Electron. Pack. Manu., 27-3. 2004, 164 Available: https://doi.org/10.1109/ TEPM.2004.843109

[13] Jafarpour, H., Moghadasi, J., Khormali, A., Petrakov, D. G., \& Ashena, R. Increasing the stimulation efficiency of heterogeneous carbonate reservoirs by developing a multi-bached acid system. Journal of Petroleum Science and Engineering, 172, 2019, 50-59. doi:10.1016/j.petrol.2018.09.034

[14] Kazmina, I., Lukyanov, P., Zhminko, N., Savchenko, I., Yusupova, G., \& Zatsarinnaya, E. Fourth industrial revolution-engineering innovations for labor productivity increasing. Talent Development and Excellence, 2020, 12, 477-487.

[15] Kazmina, I. V., Shafranskaya, C. Y., Saenko, I. I., Kozhemov, S. I., Gayazova, S. R., \& Zatsarinnaya, E. I. An economic security management system of an enterprise in the digital economy. Talent Development and Excellence, 12, 2020b, 454-466.

[16] Krasnova, L.A. International Journal of Technology Enhanced Learning, 12(1), 2020, pp. 38-52. Available: https://doi.org/10.1504/IJTEL.2020.103814

[17] Krasnova, L. A. Astra Salvensis, 5 (10), 2017, pp. 307314.

[18] Khormali, A., Petrakov, D. G., \& Nazari Moghaddam, R. Study of adsorption/desorption properties of a new scale inhibitor package to prevent calcium carbonate formation during water injection in oil reservoirs. Journal of Petroleum Science and Engineering, 2017, 153, 257-267. doi:10.1016/j.petrol.2017.04.008

[19] Kuznetsov, V. S., \& Suprun, I. K. The assessment of alumina production waste impact on natural water. Journal of Ecological Engineering, 2018, 19(2), 154-158. doi:10.12911/22998993/82267

[20] Kihyun Y. and Park J. US Patent App. 29/566,709, 2017.

[21] Leabman, M.A. and Brewer G.S.- US Patent App. 13/946,128, 2015.

[22] Liu. C., Cho C.K. and Wang T.H. Car monitor. US Patent App. 29/549, 244, 2017.

[23] Minakhmetova A.Z., Pyanova E.N., Bochkareva N.G., Borisov V. V. Digital Socialization of Teenagers. Talent Development and Excellence, 2020, 12(3s), 292-300.

[24] Movchan, I. B., \& Yakovleva, A. A. Refined assessment of seismic microzonation with a priori data optimisation. Journal of Mining Institute, 2019, 236, 133-141. doi:10.31897/PMI.2019.2.133

[25] Mizutani, S. Car electronics. Warrendale, PA: Society of Automotive Engineers, 1993.

[26] Panfilova, E., Dzenzeliuk, N., Domnina, O., Morgunova, N., \& Zatsarinnaya, E. The impact of cost allocation on key decisions of supply chain participants. International Journal of Supply Chain Management, 2020, 9(1), 552558.

[27] Petrov, D., \& Movchan, I. Comprehensive evaluation of anthropogenic load on environment components under conditions of ferroalloys manufacture. Ecology, Environment and Conservation, 23(1), 2017, 539-543.

[28] Prodanova, N., Savina, N., Kevorkova, Z., Korshunova, L., \& Bochkareva, N. Organizational and methodological support of corporate self-assessment procedure as a basis for sustainable business development. Entrepreneurship and Sustainability Issues, 2019, 7(2), 1136-1148. doi:10.9770/jesi.2019.7.2(24)

[29] Prodanova, N. A., Savina, N. V., Dikikh, V. A., Enina, Y. I., Voronkova, O. Y., \& Nosov, V. V. Features of the coherent presentation of information in order to prepare integrated corporate reporting. Entrepreneurship and Sustainability Issues, 2020, 7(3), 2227-2281. doi:10.9770/jesi.2020.7.3(54)

[30] Rahman, P. A. Parallelization of combinatorial search when solving knapsack optimization problem on computing systems based on multicore processors. Journal of Physics: Conference Series, 2018, 1015(2). https://doi.org/10.1088/1742-6596/1015/2/022015

[31] Safiullin, M. R. Digital transformation of a university as a factor of ensuring its competitiveness. International Journal of Engineering and Advanced Technology, 2019, 9(1), 7387-7390. doi:10.35940/ijeat.A3097.109119

[32] Samedov, M. N. O. et al. Biosciences Biotechnology Research Asia, 12(3), 2015, pp. 2711-2722. 
International Journal of Engineering Research and Technology. ISSN 0974-3154, Volume 13, Number 9 (2020), pp. 2484-2490

(c) International Research Publication House. https://dx.doi.org/10.37624/IJERT/13.9.2020.2484-2490

[33] Samusenko, A. S., Plaskova, N. S., \& Prodanova, N. A. The analysis of the external environment to determine the practical focus of applied research and development in the framework of innovation, 2020. doi:10.1007/978-3-03044703-8_27

[34] Savina, N. N. Major factors of teachers' resistance to innovations. Ensaio, 2019, 27(104), 589-609. doi:10.1590/S0104-40362019002701807

[35] Shurygin, V. Y. and Sabirova F.M. Espacios, 38(40), 2017, 39. Available: http://www.revistaespacios.com /a17v38n40/17384039.html

[36] Shurygin, V. Y. Astra Salvensis, 2017 (Suppl. 1), 2017, pp. 47-54.

[37] Voronkova, O. Y., Sadykova, L. R., Avdeev, Y. M., Murzagalina, G. M., Surikov, Y. N., \& Zatsarinnaya, E. I. Education in the field of technological entrepreneurship, based on the university's innovative resource base. Talent Development and Excellence, 2020, 12(SpecialIssue3), 444-453.

[38] Yemelyanov, V. A., Yemelyanova, N. Y., Morozova, O. A., \& Nedelkin, A. A. Specialized computer system to diagnose critical lined equipment. Paper presented at the Journal of Physics: Conference Series, 2018, 1015(5) doi:10.1088/1742-6596/1015/5/052032

[39] Yemelyanov, V., Yemelyanova, N., \& Nedelkin, A. Diagnostic system to determine lining condition. Paper presented at the MATEC Web of Conferences, 2018b, 172 doi:10.1051/matecconf/201817204001

[40] Yulmetyev, R. M. and Galeev, R. I. Physics Letters A, 202(4), 1995, pp. 258-262.

[41] Yulmetyev, R. M. Physica A: Statistical Mechanics and its Applications, 242(3-4), 1997, pp. 509-521.

[42] Ziebart, W. Eighth International Conference on Automotive Electronics, London, UK, 1991, pp. 1-6. 